\title{
Fasilitas Bermain Jungkat Jungkit Untuk SLB Untung Tuah Samarinda
}

\author{
Noor Qalby $^{1 *}$, Etwin Fibrianie Suprapto ${ }^{2}$ \\ ${ }^{1,2}$ Program Studi Desain Produk, Jurusan Desain, Politeknik Negeri Samarinda, Samarinda, Indonesia
}

\begin{abstract}
Special School is an educational institute who help special needs children to study with special education provided for them. There is one of Special School located in Samarinda City named Untung Tuah Special School. Just like children in general, special needs children in Special Schools need to play too, that is why there are playground in Special Schools in order for children to not feel depressed during their study. But unfortunately, normal playground facility does not have special safety function for special needs children so some them are not able to use the playground equipments. Seesaw train to cooperate, communicate, social interact, and vestibular system or balance so it is suitable for children to train their feet, hand, etc. The purposeof this design is to create seesaw facility that can help children with special needs, especially intellectual disability and physical disability children, so they can play safelydan comfortable with their friends. The design processs used Vinod Goel's method that covers formulation of the problem, literature review, data analysis, design analysis, alternative design development, and design final result that are technique drawing, 3D Modeling, prototype, and poster. This design produce a playground equipment asseesaw for special needs children especially intellectual disability and physical disability children. This seesaw is expected to be a safe playground equipment and facilitate special needs children to play freely.
\end{abstract}

Keywords: Seesaw, special needs children, special school

\begin{abstract}
Abstrak
Sekolah Luar Biasa (SLB) adalah lembaga pendidikan yang membantu anakberkebutuhan khusus untuk belajar dengan metode belajar khusus untuk mereka. Salah satu SLB yang berada di Kota Samarinda adalah Sekolah Luar Biasa Untung Tuah. Layaknya anak pada umumnya, anak-anak berkebutuhan khusus di SLB juga perlu bermain, karena itu di SLB tersedia taman bermain agar mereka tidak tertekan selama masa pembelajaran. Tetapi sayangnya, fasilitas bermain biasa tidak memiliki fungsi khusus keamanan untuk anak berkebutuhan khusus sehingga beberapa ABK tidak dapatmemakai sarana bermain tersebut. Jungkat-jungkit melatih kerjasama, komunikasi, interaksi sosial, dan sistem vestibular atau keseimbangan sehingga cocok untuk anak- anak dalam melatih kekuatan tangan, kaki. Tujuan dari perancangan ini adalah membuat fasilitas bermain jungkat-jungkit yang dapat membantu anak berkebutuhan khusus, khususnya tunagrahita dan tunadaksa, sehingga mereka dapat bermain dengan aman dan nyaman bersama teman-teman mereka. Proses perancangan menggunakan metode Vinod Goel yang meliputi perumusan masalah, tinjuan pustaka, analisis data, analisis desain, pengembangan alternative desin, serta hasil akhir desain yaitu gambar teknik, 3D Modeling, prototype, dan poster. Perancangan ini menghasilkan sebuah produk permainan berupa jungkat-jungkit khusus anak SLB terutama tunagrahita dan tunadaksa. Jungkat-jungkit ini diharapkan dapat menjadi fasilitas bermain yang aman dan mempermudah anak berkebutuhan khusus untuk bermain dengan leluasa.
\end{abstract}

Kata kunci: Jungkat-jungkit, anak berkebutuhan khusus, Sekolah Luar Biasa

\footnotetext{
* Corresponding author : etwinf@gmail.com
} 


\section{Pendahuluan}

Anak berkebutuhan khusus atau yang dulu disebut sebagai anak luar biasa, adalah anak yang mengalami kelainan atau ketunaan, baik pada satu macam kelainan maupun lebih dari satu jenis kelainan. Yang termasuk kedalam ABK antara lain: tunanetra, tunarungu, tunagrahita, tunadaksa, tunalaras, kesulitan belajar, gangguan prilaku, anak dengan gangguan kesehatan.

Menurut Hallahan dan Kauffman [1], anak berkebutuhan khusus didefinisikan sebagai anak yang memerlukan pendidikan dan layanan khusus untuk mengembangkan potensi kemanusiaan mereka secara sempurna. Dalam rangka memenuhi kebutuhan hidupnya, mereka membutuhkan bantuan layanan pendidikan, layanan sosial, layanan bimbingan, dan berbagai jenis layanan lainnya yang bersifat khusus.

Sekolah Luar Biasa (SLB) ialah lembaga pendidikan yang membantu anak berkebutuhan khusus untuk belajar layaknya anak pada umumnya dengan metode belajar yang disesuaikan dengan murid dan produk pembelajaran yang khusus untuk mereka. Masing-masing SLB dibagi berdasarkan bidang pembelajaran utama mereka yaitu SLB A diperuntukkan bagi anak tunanetra, SLB B untuk tunarungu, SLB C untuk tunagrahita, SLB D tunadaksa, SLB E tunalaras, dan SLB G untuk tunaganda [2].

Salah satu SLB yang berada di Kota Samarinda adalah Sekolah Luar Biasa Untung Tuah, SLB ini berlokasi di Jl. Samratulangi Samarinda Seberang. Sekolah ini merupakan sekolah bagian C dan D, yaitu sekolah yang berfokus pada anak tunagrahita dan juga tunadaksa.

Tunagrahita ialah istilah yang digunakan untuk menyebut anak yang mempunyai kemampuan intelektual di bawah rata-rata [3]. Tunagrahita dapat disebut juga retardasi mental, tetapi istilah tersebut pada dasarnya mengandung arti yang sama, yaitu anak yang memiliki fungsi intelektual umum di bawah rata-rata secara signifikan yang berkaitan dengan gangguan dalam penyesuaian perilaku yang terwujud atau terjadi selama periode perkembangan [4]. Istilah Tunagrahita sendiri diambil dari kata tuna yang artinya merugi dan grahita yang berarti pikiran.

Tunadaksa adalah suatu kondisi ketidakmampuan anggota tubuh dalam melaksanakan fungsinya yang disebabkan oleh berkurangnya kemampuan anggota tubuh untuk melaksanakan fungsinya secara normal [5]. Istilah tunadaksa berasal dari kata tuna yang berarti merugi dan daksa yang berarti tubuh. Penyebab tunadaksa ini bisa diakibatkan karena luka, penyakit atau pertumbuhan yang tidak sempurna.

Layaknya anak pada umumnya, anak-anak berkebutuhan khusus di Sekolah Luar Biasa juga bermain agar mereka tidak tertekan dalam masa pembelajaran mereka di sekolah. Bermain merupakan kegiatan yang dilakukan oleh setiap anak. Dalamkamus besar bahasa Indonesia disebutkan bahwa yang dimaksud dengan bermain adalah berbuat sesuatu untuk menyenangkan hati (dengan alat tertentu atau tidak). Dalam psikologi, Joan Freeman dan Utami Munandar [6] mendefinisikan bermain sebagai suatu aktivitas yang membantu anak mencapai perkembangan yang utuh, baik fisik, intelektual, sosial, moral dan emosional.

Biasanya taman bermain memiliki pilihan sejumlah jenis wahana permainan yang berbeda dan anak-anak dapat memilih dengan leluasa di mana dia ingin bermain. Fasilitas taman bermain di Sekolah Luar Biasa sama dengan sekolah pada umumnya, tetapi sayangnya fasilitas bermain biasa kurang dapat membantu anak-anak berkebutuhan khusus dengan baik. Sarana bermain pada umumnya tidak memilikifasilitas atau fungsi khusus keamanan untuk anak berkebutuhan khusus sehingga beberapa ABK tidak dapat memakai sarana bermain tersebut dan mereka tidak dapat bermain seperti anak-anak lainnya. Di SLB Untung Tuah sendiri hanya terdapat 2 permainan outdoor yaitu perosotan dan papan titian. Untuk anak tunagrahita, mereka memerlukan permainan yang dapat mengasah membantu otak mereka dalam mengingat, seperti bermain sambil belajar. Kemudian khusus anak tunadaksa memerlukan mainan yang dapat mereka akses dengan mudah dan juga aman untuk mereka. Jungkat-jungkit merupakan salah satu permainan yang ada di taman bermain, dimainkan oleh 2 orang atau lebih yang memerlukan kerja sama antar 2 sisi untuk dapat memainkannya. Permainan ini dapat dimainkan anak tunadaksa karena dudukannya dapat diturunkan sehingga memudahkan anak tunadaksa naik atau dibantu naik jika mereka memiliki kekurangan fisik kaki.

Karena itu diperlukan fasilitas bermain jungkat-jungkit yang dapat memudahkan anak tunagrahita dan tunadaksa dalam belajar dan bermain yang aman, sekaligus menyenangkan untuk mereka. 


\section{Metode Perancangan}

Dalam mendesain produk ini, agar lebih terarah,yaitu dengan menggunakan metode perancangan Vinod Goel [7], meliputi:

\subsection{Perumusan Masalah}

Sekolah Luar Biasa Untung Tuah Samarinda belum memiliki saranapermainan jungkat-jungkit yang dapat dimainkan untuk anak berkebutuhan khusus.

\subsection{Tinjauan Pustaka}

Meliputi Studi eksisting tentang jenis jungkat-jungkit dan permainan edukasi yang sudah ada, teori segmentasi terdiri dari segmentasi geografi dan segmentasi demografi. Teori ergonomi dan antropometri, Teori sistem yang digunakan meliputi sistem sambung, sistem putar, dan finishing. Teori material untuk digunakan pada fasilitas bermain jungkat-jungkit, teori bentuk dan teori warna.

\subsection{Analisis \& Spesifikasi Desain}

Meliputi Analisis pasar, studi aktivitas dan kebutuhan, analisis ergonomi dan antropometri, analisis konfigurasi, analisis material, analisis bentuk, analisis warna dan analisis produksi; Spesifikasi desain meliputi pengguna, dimensi, komponen, sistem, material, bentuk, dan warna untuk fasilitas bermain jungkat-jungkit untuk anak SLB Untung Tuah Samarinda.

\subsection{Alternatif Desain}

Alternatif desain berupa beberapa desain awal. Desain desain ini dianalisa sesuai spesifikasi yang telah ditetapkan untuk didapatkan atribut desain yang.

\subsection{Pengembangan Desain Alternatif dan Analisis}

Dari beberapa desain awal yang terpilih dikembangkan menjadi beberapa desain pengembangan. Selanjutnya desain pengembangan ini dianalisa sampai didapatkan desain final siap produksi.

\subsection{Desain Akhir}

Desain akhir meliputi gambar presentasi; Gambar teknik; Studi model; Prototype produk; 3D Model, poster dan portofolio

\section{Hasil dan Pembahasan}

\subsection{Analisis Pasar}

Analisis pasar bertujuan untuk menentukan sasaran dari produk yang dibuat sehingga didapatkan sasaran konsumen yang tepat. Keberhasilan penjualan produkdapat ditentukan oleh ketepatan strategi pemasaran yang di terapkannya dengan dasar memeperhatikan situasi dan kondisi dari analisis pasarnya. Penentuan target pasar dapatdilakukan sebagai berikut:

Untuk produk jungkat-jungkit Sekolah Luar Biasa (SLB), segmentasi geografis yang ditentukan adalah di Kota Samarinda, khususnya di Sekolah Luar Biasa Untung Tuah. Berdasarkan umur, pengguna jungkat-jungkit SLB ini didesain khusus untuk anak-anak di Sekolah Luar Biasa yang berumur 7-12 tahun. Manfaat utama dalam fasilitas bermain jungkat-jungkit anak SLB ini didesain khusus agar pengguna yang memakainya tetap aman selama bermain. Kemudian fasilitas ini juga untuk melatif saraf motorik dan sensorik mereka.

\subsection{Ergonomi dan Anthropometri}

Analisis Ergonomi dan Anthropometri diperlukan karena setiap produk perlu mengutamakan kenyamanan dalam penggunaan produk tersebut. Kenyamanan pengguna dalam menggunakan fasilitas bermain ditentukan oleh ukuran dimensi tubuh manusia.

Berikut analisis Anthropometri pada fasilitas bermain anak SLB:

Tinggi jungkat-jungkit adalah jarak tinggi dari tanah sampai pipa besi yang akan diduduki. Tingginya diambil dari tinggi lutut $50 \%$ tile yaitu $39.28 \mathrm{~cm}$, dan dibulatkan menjadi $40 \mathrm{~cm}$. Ukuran panjang maksimal dari jungkat-jungkit diambil dari dua kali panjang rentang tangan ke samping 95\% tile yaitu 145,91 cm dikali 2, yaitu 291,82 cm. Ukuran ini adalah ukuran maksimal. Ukuran yang dirancang adalah $290 \mathrm{~cm}$. Ukuran lebar dudukan dari jungkat-jungkit diambil dari lebar pinggul 95\% yaitu 31,19 cm, dibulatkan menjadi $35 \mathrm{~cm}$. Ukuran tinggi pegangan diambil dari ukuran tinggi bahu dalam posisi duduk 5\% tile dengan ukuran $34,42 \mathrm{~cm}$. Ukuran ini adalah ukuran maksimal, ukuran yang dirancang adalah $24 \mathrm{~cm}$. Diameter pegangan diambil dari 50\% tile panjang tangan 14,47 cm. Diameter yang dirancang adalah $10 \mathrm{~cm}$. Ukuran tinggi papan panel permainan edukasi diambil dari tinggi tubuh anak5\% tile $104,57 \mathrm{~cm}$. Ukuran yang dirancang adalah $110 \mathrm{~cm}$. Ukuran lebar papan panel permainan edukasi diambil dari lebar sisi bahu $95 \%$ tile yaitu $36,93 \mathrm{~cm}$. Ukuran yang dirancang adalah $40 \mathrm{~cm}$. 


\subsection{Sistem}

Analisis sistem dilakukan untuk menentukan sistem yang sesuai untuk diaplikasikan pada fasiltias bermain anak SLB. Sistem-sistem yang akan diaplikasikan adalah sebagai berikut:

\section{Sistem Sambung}

Berdasarkan hasil analisis kelebihan dan kekurangan system sambung, system sambung yang sesuai untuk diaplikasikan pada produk adalah sambungan Mur, Baut, dan Las Besi. Las besi memiliki kekuatan sambung yang kuat untuk dijadikan sistem sambung pada mainan yang aktif dalam bergerak. Sambungan permanen ini juga diperlukan pada produk jungkat-jungkit yang dimainkan outdoor sehingga walaupun terkena paparan sinar matahari dan hujan, sambungan tetap kuat. Kemudian mur dan baut dapat dengan mudah dibongkar pasang untuk bagian yang tak menggunakan las atau jika ada bagian yang tidak ingin disambung secara permanen agar dapat diperbaiki kembali.

\section{Sistem Putar}

Berdasarkan hasil analisis, sistem putar yangsesuai untuk diaplikasikan pada produk fasilitas bermain anak SLB adalah sistem putar baut besi. Sistem putar besi kuat dan tahan lama, pemasangannya juga lebih mudah dari system yang menggunakan bearing. Karena menggunakan baut besi yang ukurannya besar dan panjang, tidak perlu khawatir dengan kekuatannya.

\section{Finishing}

Berdasarkan hasil analisis, finishing yang sesuai untuk diaplikasikan pada produk fasilitas bermain anak SLB adalah finishing menggunakan cat duco. Cat duco memiliki banyak pilihan warna karena sebuah permainan untuk anak diperlukan warna yang cerah dan menarik untuk mereka. Kemudian finishing menggunakan memberikan hasil yang mulus sehingga tidak menghilangkan estetika dari produk.

\subsection{Analisis Material}

Kebutuhan material untuk fasilitas bermain jungkat-jungkit ini harus kuat menahan beban, tahan cuaca panas atau atau hujan, dan aman dimainkan untuk anak-anak. Oleh karena itu, diperlukan material yang sesuai dengan kriteria yang telah disebutkan sebagai rangka dan body.

\section{Material Rangka}

Dalam memilih material, syarat-syarat yang harus dipertimbangkan adalah material tersebut harus kuat untuk menahan beban dari anak-anak yang bermain, tahan cuaca panas atau hujan, perawatannya mudah, bahannya mudah didapat, dan harganya sesuai.

Berdasarkan hasil analisis yang telah dilakukan, material rangka yang sesuai untuk diaplikasikan pada produk fasilitas bermain jungkat-jungkit SLB adalah material Pipa Besi. Pipa besi dipilih karena bahannya yang tahan cuaca juga harganya yang lebih murah disbanding stainless steel.

Karena pipa besi dipilih sebagai material rangka, selanjutnya adalah mencari ukuran diameter yang akan digunakan. Ukuran diameter yang dipilih adalah ukuran 3", karena jika lebih kecil dari 3" maka pipa tersebut tidak akan kuat untuk menahan beban anak, pipa yang lebih kecil dari 3" lebih cocok menjadi bagian sandaran dari jungkat-jungkit. Dan jika lebih besar dari 3" seperti 4" dan seterusnya maka pipa besi akan jadi berat dan daya hentakannya dapat berbahaya untu kanak-anak. 3" adalah ukuran diameter yang sesuai untuk diterapkan sebagai rangka dari jungkatjungkit. Juga tambahan pipa besi ukuran 1" untuk material tambahan sebagai rangka kursi jungkat-jungkit.

\section{Material Body}

Dalam memilih material yang digunakan sebagai body, syarat-syarat yang harus dipertimbangkan adalah material tersebut harus kuat karena perlu menahan beban dari anak-anak yang bermain, tahan cuaca dari panas atau hujan, bahan mudah didapat, tidak terlalu berat dan harganya sesuai.

Berdasarkan analisis yang telah dilakukan, material body yang sesuai untuk diaplikasikan pada produk adalah plat besi. Plat besi merupakan material yang kuat, tidak mudah patah jika dimainkan, tahan di cuaca panas dan hujan. Tebal yang yang sesuai untuk digunakan sebagai body adalah plat besi setebal $5 \mathrm{~mm}$.

\section{Material Pendukung}

Material yang digunakan sebagai material pendukung yaitu stiker. Syarat yang harus dipertimbangkan adalah material tersebut harus tahan cuaca dari panas atau hujan, bahan mudah didapat, warna tidak mudah pudar.

Berdasarkan analisis yang telah dilakukan, material stiker yang sesuai untuk diaplikasikan pada produk adalah stiker ritrama. Stiker ritrama banyak diaplikasikan pada kendaraan seperti motor dan mobil dan mudah ditemukan dibeberapa printing service besar. 


\subsection{Analisis Bentuk}

Berdasarkan hasil analisis, gaya desain yang cocok untuk diaplikasikan pada produk yaitu gaya desain modern dengan bentuk hewan. Gaya modern dipilih karena bentuk modern memiliki banyak keragaman desain yang dapat dibuat melihat dari perkembangan jaman hingga sekarang. Bentuk hewan dipilih karena bentuk hewan akan menarik perhatian anak untuk memainkannya. Dengan melihat bentuk hewan, orang-orang akan segera tahu bahwa jungkatjungkit inidikhususkan untuk anak-anak.

\subsection{Analisis Warna}

Analisis warna diperlukan guna menentukan warna yang sesuai untuk diaplikasikan pada jungkat-jungkit SLB. Pendekatan yang dilakukan dalam analisis ini adalah dengan mengetahui warna apa yang sering dipakai dalam permainan atau playground khusus untuk anak berkebutuhan khusus.

Warna yang dipakai merupakan warna yang tidak terlalu terang dan tidak terlalu redup sehingga tidak melelahkan mata anak dan tidak mengganggu penglihatan anak berkebutuhan khusus. Terdapat juga warna yang gelap, tetapi warna gelap yang tidak segelap warna hitam, tidak memiliki banyak cahaya dan mengganggu mata anak.

Berdasarkan hasil analisis, warna yang sesuai diterapkan pada produk adalah warna hijau sebagai warna dominan. Warna hijau dipilih karena dapat menenangkan tubuh dan pikiran, mengurangi kecemasan, juga mendorong konsentrasi pada anak. Warna hijau adalah warna yang menonjolkan sifat natural, warna hijau memberikan ketenangan, back to nature, alami. Selain itu, hijau merupakan warna yang paling aman, banyak disukai dan salah satu warna terbaik untuk lingkungan anak autis. Kemudian untuk warna aksen menggunakan warna krim karena warna krim merupakan warna yang tidak terang dan juga tidak gelap. Jika hijau merupakan warna yang menyejukkan,maka krim menjadi warna yang menghangatkan. Warna hijau dan krim merupakan kombinasi warna natural dan alami, warna ini dapat ditemukan dikehidupan sehari-hari,warna yang tidak akan mengganggu mata tergantung intensitas cahayanya.

\subsection{Proses Desain}

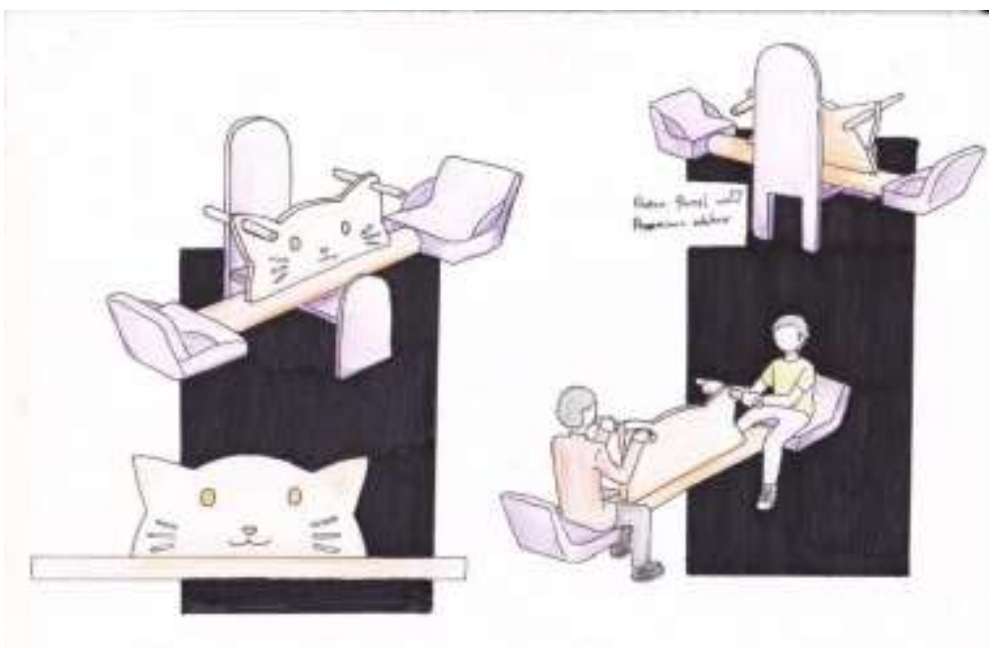

Gambar 1. Desain Awal terpilih

Desain awal dalam gambar 1 memiliki bentuk hewan yaitu kucing, kelebihannya bentuk hewan banyak disukai anak dan desainnnya cukup sederhana. Sedangkan kekurangan dari desain ini kursi dan pipanya terlalu tebal dan akan membuat berat produknya. 


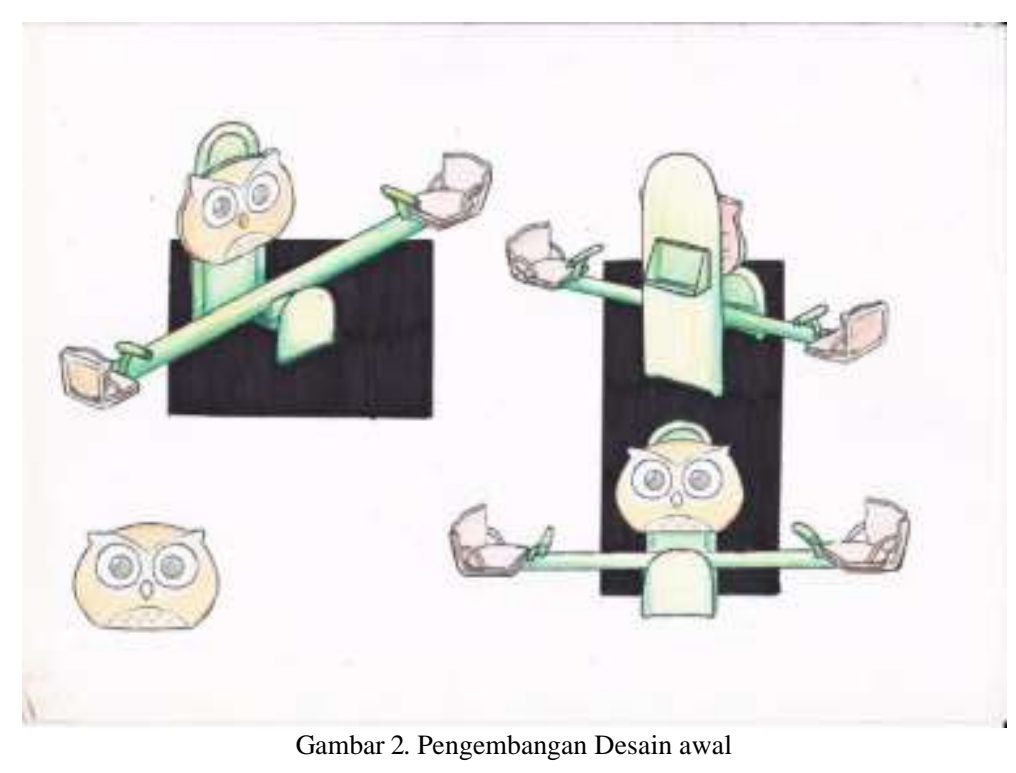

Pengembangan desain awal dalam gambar 2 ini berbentuk burung hantu. Burung hantu dikenal dan banyak digunakan sebagai simbol pengetahuan dan kebijaksanaan karena sifatnya yang jarang berkicau dan banyak diam atau mendengar. Kelebihannya, anak-anak dapat belajar mengenai burung hantu karena burung ini sangat jarang ditemui, dan juga belajar dari sifat burung hantu untuk menjadi diri yang bijaksana. Burung hantu dipasang di bagian tiang agar saat dimainkan tidak mengganggu. Sandarannya berbentuk siluet dari burung hantu sehingga desainnya cocok dengan tema. Kemudian di belakang sandarannya diberi besi rangka agar sandaran lebih kuat dan tidak mudah terlepas.

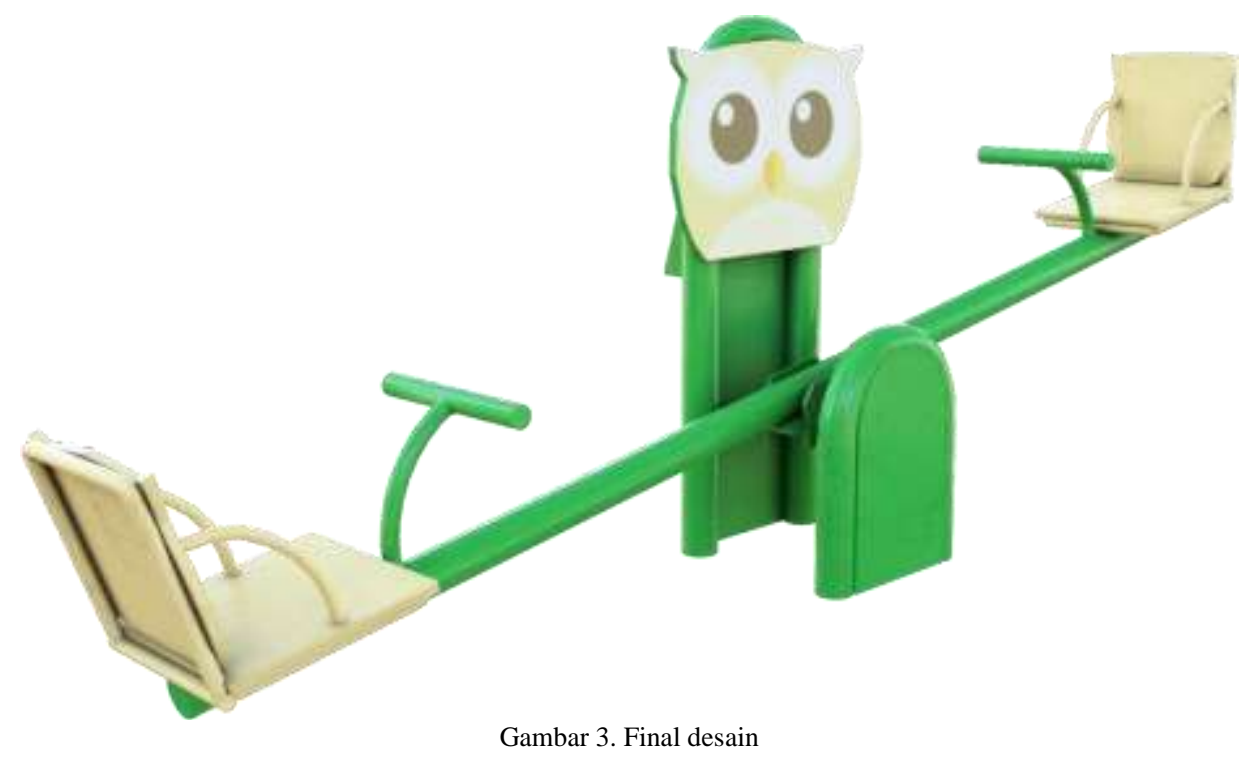




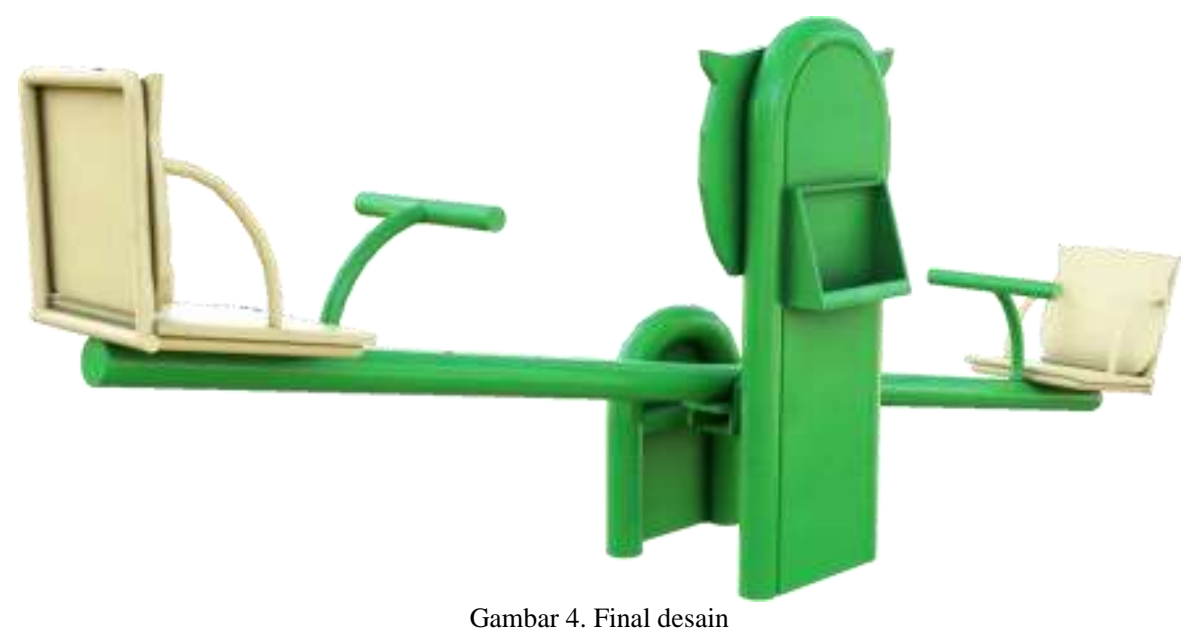

\section{Kesimpulan}

Berdasarkan hasil perancangan dan pembuatan Fasilitas Bermain Jungkat-Jungkit Untuk SLB Untung Tuah Samarinda, maka dapat ditarik kesimpulan: Jungkat- jungkit ini dirancang agar dapat digunakan oleh anak berkebutuhan khusus yaitu tunagrahita dan tunadaksa. Menggunakan gaya desain modern dengan bentuk hewan dan memakai warna yang cocok untuk anak berkebutuhan khusus. Menggunakan sistem sambung las dengan material besi yang kuat dan tebal.

Perancangan produk ini masih terdapat beberapa kekurangan. Untuk mendapat hasil yang maksimal perlu adanya pengembangan lebih lanjut. Ke depannya diharapkan adanya perancangan lanjutan mengenai jungkat-jungkit ataupun fasilitas bermain untuk anak berkebutuhan khusus. 


\section{Daftar pustaka}

1. Daniel P Hallahan, J.M.K., Exceptional children: Introduction to special education. Vol. 3. 1986, New Jersey: Prentice Hall.

2. Jenis-Jenis Sekolah Luar Biasa. 2015 [cited 201712 Oktober]; Available from: news.okezone.com/read/2015/12/03/65/1260354/jenis-jenis- sekolah-luar-biasa.

3. Somantri, S., Psikologi Anak Luar Biasa. 2006, Bandung: PT. Refika Aditama

4. Daniel P Hallahan, J.M.K., Exceptional children: Introduction to special education. Vol. 2. 1982, New Jersey: Prentice Hall.

5. Efendi, M., Pengantar Psikopedagogik Anak Berkelainan. 2006, Jakarta: Bumi Aksara.

6. Joan Freeman, U.M., Cerdas dan Cemerlang. 1996, Jakarta: PT Gramedia Pustaka Utama.

7. Goel, V., Sketches of Thought. 1995, Cambridge: MIT Press 